\title{
Explorations: Teaching and Research Methods Beyond Boundaries
}

\section{Giulia Setti}

Politecnico di Milano, Department DAStU, Architecture and Urban Studies, Milan, Italy

\section{Abstract}

The essay shows a critical reflection on different forms of intensive courses (such as workshops and seminars) and on possible design outcomes. The research studies how to teach architectural design subjects is changing and how forms of 'open' learning could help to overcome barriers and disciplinary boundaries. In particular, the essay describes some experiences of intensive workshops conducted in recent years by the Politecnico di Milano in collaboration with Universities in China and India, supporting on one hand a better and deeper knowledge of other contexts, on the other, questioning the traditional teaching methodologies of the architectural design in favor of more dynamic processes. The investigated contexts lead students to reflect on the meaning of the architectural design and on its different forms in contemporary

Corresponding Author: Giulia Setti

giulia.setti@polimi.it

Received: 15 March 2019

Accepted: 25 May 2019

Published: 20 November 2019

Publishing services provided by

Knowledge E

(c) Giulia Setti. This article is distributed under the terms of the Creative Commons

Attribution License, which permits unrestricted use and redistribution provided that the original author and source are credited.

Selection and Peer-review under the responsibility of the Architecture across Boundaries Conference Committee. scenarios. The article describes the definition of these research and design activities and the principles that led to the formulation of programs and topics, useful to form student more aware of dynamics and transformations underway in contemporary cities.

Keywords: Workshop, Public Spaces, India, China.

\section{Introduction: A Critical Premise on 'Crossing' Teaching}

"A teaching worthy of this name does not frame, it is not uniform; it doesn't produce scholars, but knows how to animate the desire to know [7]".

Opening new gazes and forms of knowledge is the task of university, in particular the construction of an 'open' education, capable of capturing interests from different fields and professions, as well as coming out from the boundaries of university classrooms to explore the world and its challenges.

Architectural design methods take increasingly open forms throughout an intense exchange with different contexts and places; the ease of communication and forms of integration between different professional fields are opening up to processes of radical modification of the ways in which architectural design could develop. 
In the academic field, the opening to other international contexts has reduced and eliminated the existing boundaries: barriers that are often linked to deep-rooted relationships with the territory or with Masters and Schools. In this scenario, we are observing a rapid and increasing modification of traditional forms of teaching architectural design, and the disciplines related to this subject, which requires a revision of the tools and the dynamics of exchange processes between professors, practitioners and students and also among students themselves.

Nowadays architectural design becomes international, it allows more and more a fruitful exchange between professors of different faculties who work in various places putting their knowledge available and opening up to new realities and opportunities for the design. Through some international teaching experiences conducted in different contexts, the essay would like to highlight the challenges that overcoming barriers could bring to the academic level and how these experiences can guarantee more skills and preparation to future architects.

The proposed article aims to critical reflect on two different, but related, aspects: on one hand, the different forms of teaching that are crossing different continents, schools of thought and schools of architecture; on the other hand, to observe and to describe experimental research and teaching methods that could arise from shared forms of teaching, external to the own context of origin.

\section{Teaching Across Boundaries: Architectural Design As a Tool to Know Places}

Starting from 2014, through various opportunities, I have carried out teaching and research activities in India and in China with intensive programs (such as workshops and seminars) promoting the exchange between students of Politecnico di Milano and Universities partner of these events.

An ambitious project that allowed to understand how much the teaching ways change when the project 'goes out' from the 'local' boundaries. Overlapping different environments and methodologies of design allow to modify and to implement the teaching processes; design therefore becomes an instrument of knowledge of places, a moment of critical discussion.

Workshops built within international exchange experiences were born from the increasingly strong need among students to learn and to experience from other places, far away but more and more accessible. In particular, experiences that will be described in depth in the next chapters, show how punctual design activities, of short duration, 
could constitute an opportunity to develop further design and research work insights able to provide innovative approaches and methodologies in the architectural design field.

The contexts explored by these teaching activities try to build connections and thematic links between the European context and the city of Milan, together with the Asian context, specifically working on Shanghai (China) and Ahmedabad (India). It is not a matter of comparing contexts different by geographical location and spatial features, but to try to identify research and investigation topics that could represent crucial questions for both places. It is a complex choice that starts from an important premise: architectural design is a shared and universal dialogue tool, able to put in connections different morphological and urban conditions.

For this reason, in the definition of different (but common) topics for the workshops conducted in China and India (Workshops and experiences conducted and described in this essay refer to cooperations between the School of Architecture, Urban Planning Construction Engineering of Politecnico di Milano and CEPT University, Faculty of Architecture, Ahmedabad (India), Shanghai Jiao Tong University (China) developed in several years starting from 2015), local contexts and the dynamics in progress have always been observed, to understand what common affinities and problems could affect both places, thus constituting a training ground for the debate and discussion among students and professors. China and India represent conditions characterized by economic and urban development situations that are different from the European (and Italian) context; the Asian continent still shows a strong propulsive push to growth, both in its population and in its cities; where urban systems and conglomerates extend to accommodate a growing number of inhabitants.

How can we observe these changes and how can we support processes to better understand the current dynamics in the definition of urban settlements that lead students to question themselves beyond the 'boundary' of their place of origin? Could architectural design be a tool to explore places and issues related to urban processes?

Could we learn through different forms of observation of reality, which could be translate into greater awareness of our design tools?

'Across boundaries' could mean to build tools and design knowledge useful for training architects, urban planners to act in unstable contexts, able to change rapidly. Furthermore, a formation, academic and professional, aware of the different global conditions and the changes to which the design forms are subjected cannot currently build a deeper awareness of the fragility - and the beauty - of places. 
Design project is increasingly confronted with fleeting conditions, where the definition of a unitary and 'fix' project appears to be less and less feasible. For this reason, what teaches practicing architecture in different contexts is working with the adaptability of design solutions, defining strategies and not fix drawings, building scenarios (changeable) and not complete, fixed and stable images.

How does design change testing it on different contexts and what challenges does it create in the development of teaching methodologies and knowledge sharing tools?

Similarly, what could represent for students this kind of experiences and what impact can have on their studies in a longer time? Especially after many thoughts, stronger and stronger, that are emphazising the necessity to build a dynamic profile, able to respond to the needs, in constant change, of our society.

\section{Shanghai and Ahmedabad: Two Laboratories on Architectural Transformations}

I will take, as key examples, two workshops recently conducted in two very different contexts, such as Shanghai (China) and Ahmedabad (India); with the aim to synthesize the definition of an educational model, successfully experimented in recent years, and the relationships with territories that is able to determine.

Ahmedabad (Ahmedabad is the capital of Gujarat state, located in the northwestern part of India; it is a city with a strong industrial history, in rapid and constant evolution; in Ahmedabad there are some of India's most important universities, including CEPT University, in the field of Architecture and Design), capital of the Gujarat state, tells about a fragile urban fabric, characterized by a dense and rich historical center (the Old City) in terms of architectural and urban heritage; a growing city that has represented the heart of Indian industrial production since the 1970s.

Why we have to look at Ahmedabad and what teaching and design methodologies could be developed? The work conducted on Ahmedabad starts with the definition of an international exchange program with CEPT University (School of Architecture) and Politecnico di Milano, working on the idea to try to develop new teaching methods. Starting from the design workshop experiences, it has been made an attempt to build a 'laboratory' consisting of two annual events dedicated to the discussion of common issues in the architectural design declined differently in Milan and in Ahmedabad itself.

A 'laboratory' because, starting from 2015, the workshop has allowed more than a hundred students to work together on crucial questions for the sites investigated, in 
particular on the concept, use and role of public spaces in cities like Ahmedabad and Milan.

Public space is a definition that no longer convinces and it does not work anymore - for several reasons - neither in the European (Italian) context, nor for the Indian one. Because public space takes a fluid condition in Ahmedabad and it is no longer recognizable in the canonical figures that the Western Europe has always used to describe it.

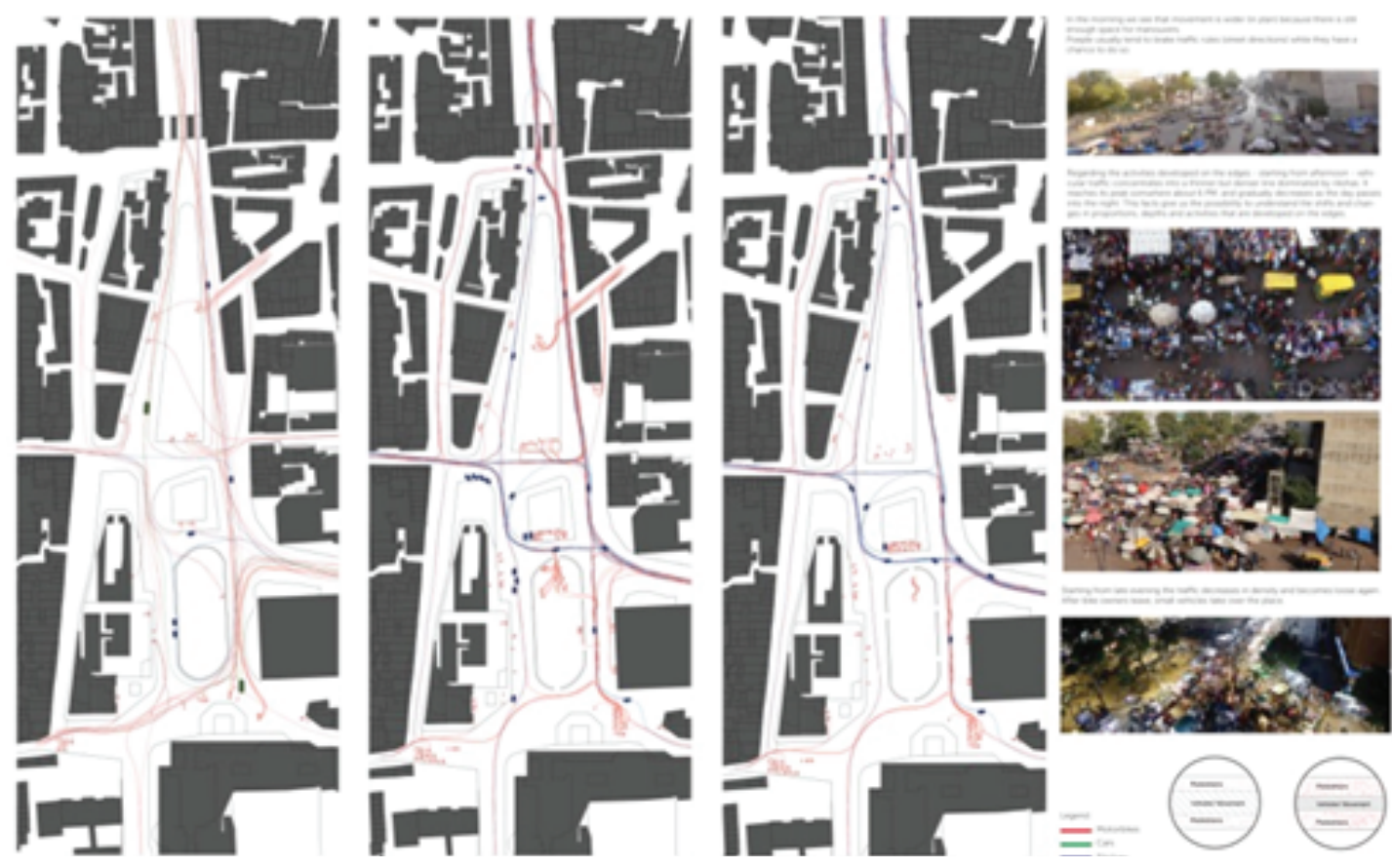

Figure 1: Ahmedabad: transition contexts; @CEPT University, Winter School 2015.

It is not the square that defines the Indian community, but it is clear that shared places and, therefore, places of events and collective activities, used from the majority of the population, are constantly changing, even in the course of a single day. The 'public' no longer identifies, and in certain contexts it has never indicated, the ownership of the land, but rather indicates forms, processes and architectures that are adapted to informally collect activities dedicated to public community.

In Europe, and in Milan in recent years, there has been an increasing and frequent re-definition of the relationship between buildings and public spaces / grounds; a modification that finds its origins in the latent tensions [2] that have accompanied the definition of some of the last urban projects in the city (thinking about transformations of City Life or Porta Nuova, in Milan).

In this context, the client has changed radically, more and more strongly in the hands of privates, and also the redefinition of the role of public space designed to 'give back' 
for what has been built. A public space that, once again, loses its paradigmatic features and becomes controlled, managed and maintained by private individuals. This has generated in the city different responses in terms of uses of space and architectural models that has been built; at the same time, however, it opens up to possible new readings of public or semi-public urban space.

In this perspective, design processes carried out during the different workshops highlighted the centrality of a change of paradigm in the definition of open and shared spaces; marked in some cases by the need to be flexible and adaptable to different temporal conditions.

In Ahmedabad, the street is one of the most public contexts of the city, it is a place of informal markets, small kiosks and restaurants, temporal activities that become alive during the day. How to map, identify and consider these different and changing activities in the public space project with the idea of supporting and encouraging the organization of informality; a paradox that however appears to be also at the center of various public administration policies that are favoring a more 'organized' disposition of activities and salespeople.

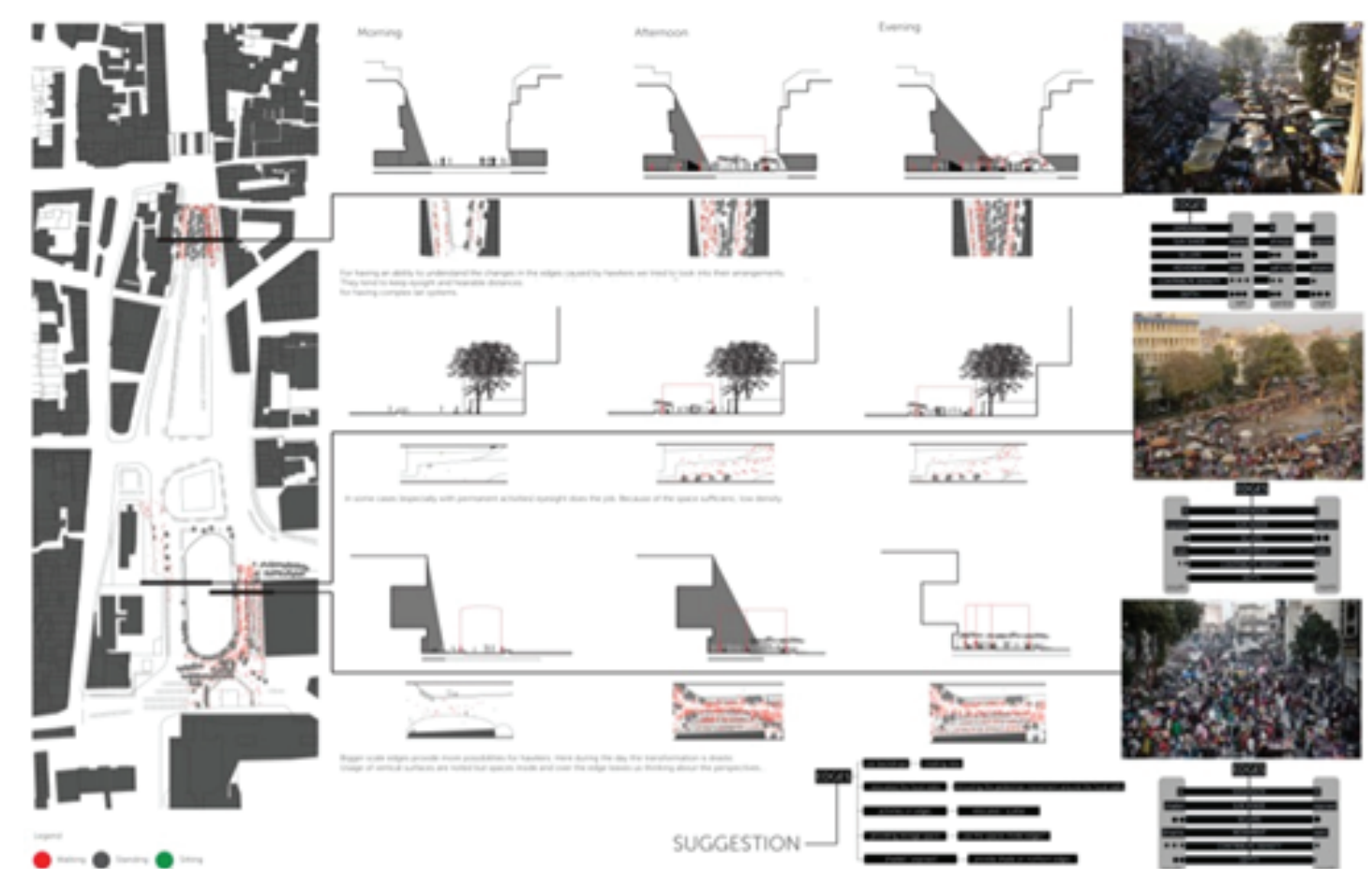

Figure 2: Ahmedabad: Edge Conditions; @CEPT University, Winter School 2015.

Students were asked, therefore, to try to observe and describe temporary phenomena and the related consequences in the urban fabric and on the buildings that come to define these spaces. To describe unstable phenomena, the different working groups 
have necessarily had to question themselves on the forms and ways in which to represent and critically investigate different and less traditional processes. The laboratory has become a collective research on the forms of representation of architecture and on the role of the design in the definition of more coordinated and ordered processes between them.

The second experience that this short essay proposes to describe regards, instead, the Chinese context and, in particular, a series of workshop experiences conducted at the Shanghai Jiao Tong University and the Xi'an Jiao Tong University in 2018 and 2016.

Workshops of a different nature that show how the culture and the dimension of exchange promoted in recent years by the Politecnico di Milano has been able to 'open' boundaries and cross different barriers, favoring forms of cooperation and joint activities between students and professors.

The most significant experience, from this point of view, is linked to the workshop conducted in July 2018 at Shanghai Jiao Tong University (The workshop called "Strategic Design for the Enhancement of Architectural, Urban \& Environmental Resources" took place at Shaghai Jiao Tong University from 11 to 26 July 2018 in partnership with Politecnico di Milano; Scientific Committee: Ilaria Valente, Ma Wenjun, Marco Bovati, teaching staff: Ma Wenjun (SJTU), Huang Jianyun (SJTU), Marco Bovati (Polimi), Giulia Setti (Polimi), Marco Trisciuoglio (Polito)) where students from the Politecnico di Milano and SJTU worked intensively together on the design of an abandoned area in the heart of the Bund in Shanghai. A different design exercise compared to what was described before, which highlighted equally significant issues for students, architects and professors; on one hand, the need for the project to dialogue and to fit into the heart of traditional Chinese fabric, where the presence of traditional residential typologies, such as the 'lilong', opens a debate on which forms and conditions the design must preserve by fitting into these contexts.

At the same time, it appears significant to read the transformation of this plot into a broader growth scenario, that sees Shanghai rapidly growing and changing its skyline - even in a few years -, raising a more delicate issue concerning 'duration' of design processes in evolving contexts and, therefore, subject to drastic and radical changes in the form and structure of settlements.

To design in the context of Shanghai highlights how the relationship between building and urban space is increasingly linked to the dynamism of the city: a city that sees its borders 'open', which is confronted with an increasing number of tourists and, therefore, with the need to make better use of its public spaces. At the same time, the architectural language that is developing in Shanghai shows a continuous overlap 


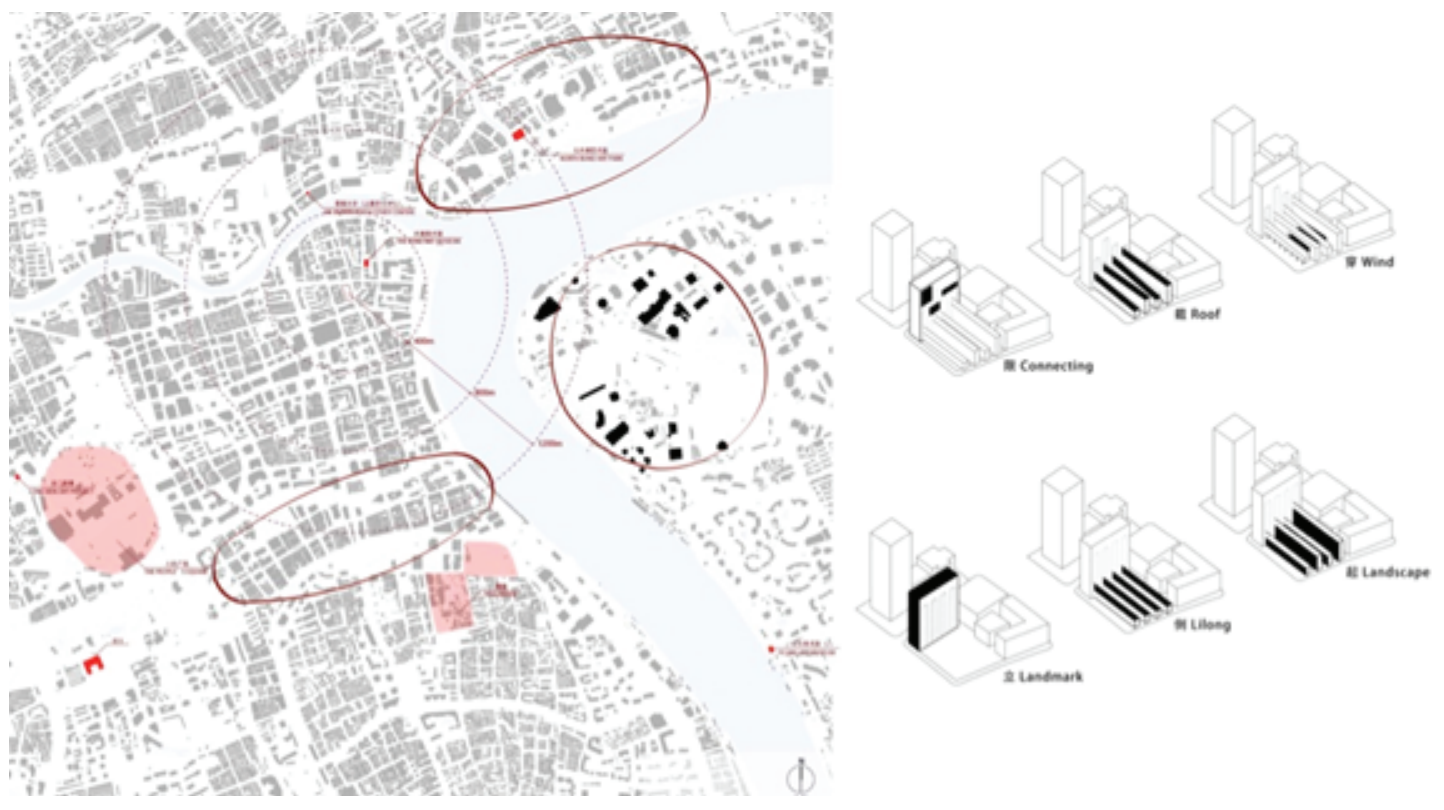

Figure 3: Shanghai: urban analysis and design strategies; @SJTU-Polimi, Summer School 2018.

of different buildings, each of these being an expression of itself and often unable to establish a dialogue with its immediate surroundings. The questions raised during the workshop also concerned the connotation of a project in the heart of Shanghai (and of the traditional Shanghai) that necessarily has to talk, or try to do so, with different 'objects' overlapped together during the past few years.

If in India the project focused on building a relationship and a reinterpretation of uses and forms of contemporary public space; in the Chinese context, it is the image of architecture itself that has become the subject of critical discussions during the workshop. Arising central issues in the contemporary debate on architectural design: how to build the image of a city and what relationship should be established with the surrounding context, in particular if tied to a traditional typological system.

The workshop held in July 2018 was born after a previous experience conducted in Milan in June 2017 (The workshop called: "Reforming Urban Voids. Farini Rail Yard in Milan" conducted from 11 to 18 May 2017 at the School of Architecture Urban Planning Construction Engineering, Politecnico di Milano was focused on the debate on the abandoned railyards in Milan and on a wider reflection on possible regeneration strategies. Scientific Committee: Ilaria Valente, Ma Wenjun, Gabriele Pasqui, Luca Basso Peressut, Carolina Di Biase), an experience that focused on similar issues to those developed in Shanghai, but declined in the context of Milan. In that case, students were pushed to propose intervention strategies for the transformation of one of the abandoned rail yard in Milan; in particular on the Farini rail yard, nowadays abandoned and subject to possible regeneration scenarios promoted by the Municipality of Milan. 
Even in that case, the questions raised set the goal of building possible connections between different contexts, which however referred to same design issues: the Farini rail yard is, for Milan, a great void in the consolidated city fabric, how to intervene and which architectural languages could be integrated? Which relationship could be established with the traditional city and its urban measures?

The work coordinated between professors and students has led to integrated experiences and visions on the future of Milan first and of Shanghai later, through a design process capable of identifying the most appropriate strategies for important urban transformations such as those described for the areas of Milan and Shanghai.

\section{From an Intensive Workshop to the Definition of Research Methods}

Which kind of methodologies could be grasped following different intensive teaching experiences in 'other' contexts?

First of all, the necessity to overcome a traditional approach to architectural design: working in 'other' contexts and crossing boundaries (cultural) the architectural and urban design expands its limits and it could be compared with different processes and conditions. This leads to abandon established visions or strategies, fixed over the time, to build and imagine projects that develop through extended times, also through different scenarios, where the design of the great urban project is modified and adapted to specific solutions, to projects developed by phases able to intercept the change taking place in the cities and its open spaces.

It is possible to learn how to design starting from the necessity of contexts that have seen rapid changes in forms and uses of their spaces and this process raises important questions about the 'life' of the architectural project (in all its forms).

And this becomes an experimental laboratory in the growth and training of future architects who could directly experience what it means to design or imagine new forms and spaces in contexts different from those in which they have worked before.

Moreover this challenge emerges strongly both in the personal path of students downstream of these experiences, and in the interest that they have developed towards a 'conscious exploration' of the world, its architectures and problems.

If the architect, as I believe, has a strong ethical role in the professional filed, linked to the social and cultural needs of countries and increasingly called to intervene on fragile and decisive topics for the future development of cities, then the architect will always have to be more able to built an open system of shared knowledge, he/she must 
be able to check knowledge and tools on the field, on the action ground of the design activities.

Shared teaching experiences among students and professors from different backgrounds and conditions could (and must) help in an increasingly difficult task: to educate curious and prepared architects, being able to learn the deepest instances and issues from each context in which they would be called to intervene. Only in this way, it will be possible to imagine cities capable of adapting to the underway changes, linked either to the growth of population or, on the contrary, to demographic contraction, to economic and social changes that imply a new debate on the urban form of our cities. During workshops conducted in the last 5 years in India, China and Italy, attempts were made to think about the construction of possible 'exportable' and adaptable teaching methods in other didactic activities like these. First of all, each intensive course has been based on a careful (and delicate) understanding of places; complex contexts, not always easy to read, that have been investigated starting from field surveys and from the contribution of involved professors; each workshop tried to build different methodologies, linked to rapid and punctual mapping and design proposal, in the form of an ex-tempore, testing the capacity to built fast scenarios and to catch characters of the place.

The activity carried out in these areas makes it possible to develop a better and deeper awareness of 'rapid time' of the design, especially in its initial phase of concept, and of a 'long duration', necessary instead for its maintenance and care.

What does it mean then to act and design beyond barriers?

To act beyond boundaries implies a dense, rapid and flexible professional and academic growth; it requires adaptability and involves a transition of design methods. Teaching architectural design is under a strong change, becoming not only an instrument of designing shapes, moreover a personal discovery and growth. Students involved in these experiences develop a more aware vision of the dynamics that organize both the professional reality and the academic context.

They know, albeit for the limited times, other places: exploring, through the design process, issues that are not related to the contexts of origin. In this sense, the experiences conducted in China (in Shanghai for example) have allowed to consolidate these relationships, to discuss and observe different ways of teaching architectural design, as well as observing rapidly evolving contexts. Architecture overcomes boundaries, today more than ever, and requires a global vision, capable of opening walls to build a conscious project.

Finally, the critical discussion on the design development is one of the prerogatives that workshops and intensive design activities manage to grow among the skills of 
involved students. The rapidity of the design process implies a double necessity: on one hand, it is necessary to find shared forms of dialogue and efficient tools to discuss ideas and to explore different design possibilities, useful to build a shared version; on the other, the design proposal development in the workshops could be seen as attempt to approach wider topics and ideally a good common ground to develop further researches such as Master Thesis.

Moreover, the working session becomes a public discussion field and a continuous way of questioning the different design proposals; in this sense it is a laboratory, precisely because it requires a continuous revision of the contents, which could be modified, through discussion, to become more structured. In the workshop experiences conducted in recent years, students have been able to learn, experiment and reflect beyond, and outside, the common boundaries. Students, who have participated, seemed enriched by these activities, that has led to build further exchanges with universities partner both in terms of internships and other didactic experiences.

Workshops have certainly contributed to strengthening the capacities of involved students, to learn other ways of developing a design project and, above all, finding similar thematics and methodologies in different contexts.

\section{Scenarios to Define the Architectural Design in the Con- temporary Era: From the 'Field' to the Theory, from The- ory to the 'Field'}

The design explorations here described tell about research activities 'field', or intense operative investigations into (and on) places, a collection of information and a sedimentation of places, activities, contexts that are profoundly different from the realities to which we are used to. For this reason, the transition from the research field to the design theory is an extremely important step in teaching experiences based in other contexts that crosses boundaries of the project.

In the development of these didactic experiments some interesting insights were born, developed both through Master Thesis and through research or dissemination of the materials produced within these activities. This shows how the intensive field research represents an essential tool for future architects to know and describe contemporary phenomena; it is also a moment of critical reflection that often leads to the individual need to continue to study a topic, to develop it with greater critical analysis.

Master Thesis's carried out after the workshops actvities conducted in Italy, China and India have worked on different ways to explore the design disciplines; not just a 
project for a place, but a way of responding, through the project, to crucial problems of communities, cities and neighborhoods.

There could not be conclusions to a research work, still in progress, but it is possible to imagine that, thanks to projects like the ones here described, open and active forms of teaching could be implemented, capable of involving and training students who are able to recognize the transformations of contexts and cities in which we live.

Through the results, and the engagment of students, each workshop made possible to redefine the contents and to reflect on what students have learnt. Beyond the initial difficulties, students have developed new skills and critical lenses, questioning their knowledge and integrating them with colleagues and professors.

The atmosphere of mutual exchange has contributed to reinforce the interest in the topics discussed within the workshops; at the same time, the continuous debate, created during these occasions, makes possible to grow, not only of the individual knowledge, but to rethink architectural design as a shared laboratory of common knowledge.

\section{References}

[1] Carmona, M., Heat, T., et al. (2003). Public places, urban spaces: the dimensions of urban design. Oxford: Architectural Press.

[2] Cerruti But, M., Kërçuku, A., Setti, G., Vassallo, I. (2017). Tensioni Urbane. Ricerche sulla città che cambia. Siracusa: LetteraVentidue.

[3] Gehl, J., Svarre, B. (2013). How to Study Public Life, Washington: Island Press.

[4] Hajer, M., Reijndorp, A. (2001). In Search of New Public Domain: analysis and strategy. Rotterdam: NAi Publishers.

[5] Healey, P., et al. (eds) (1995). Managing Cities: the New Urban Context, Chichester: John Wiley \& Sons.

[6] Mehrotra, R., Vera, F. (2015). Kumbh Mela. Mapping the Ephemeral Megacity. New Delhi: Niyogi Books.

[7] Recalcati, M. (2014). L'ora di lezione. Per un'erotica dell'insegnamento. Torino: Einaudi.

[8] Whyte, W. H. (2001). The Social Life of Small Urban Spaces. New York: Project for Public Spaces. 